\title{
How Uneducated Small Factory Owner Can Understand GST in Simple Way
}

\author{
Randhir Kumar
}

\author{
M.com, UGC NET, L. N. Mithila University, Darbhanga, Bihar, India.
}

\begin{abstract}
GST is a tax that needs to pay on supply of products and offerings. Any person, who is presenting or offering goods and services, is liable to fee GST. MSME ${ }^{e e}$ s are a major driver in the Indian economy, contributing to almost $7 \%$ of the manufacturing GDP and $31 \%$ of the services GDP. With a consistent growth rate of about $10 \%$ they employ about 120 million people and contribute to around 46\% of the overall exports from India. Under the GST regime, this significant sector too is set to change. This paper based on the survey based on the effect of the implementation of GST on the SME's in which the problems associated with the GST will be primaries and it was concluded that a lot of people were still unable to understand the working of GST and they have to make understand their customer also, most of the youngster believe that with time all the problems were automatically solved and the fair face of GST will always profitable to everyone.
\end{abstract}

Keywords: Small factory, GST.

\section{INTRODUCTION}

After independence, the biggest roundabout assessment change in India has started with products and ventures charge (GST). After much consultation, the GST bill was passed at Rajya Sabha and this winter meeting will be examined at the state get together [1]. Having the bill for incorporated national expense changes, the market is brimming with new desire among industry pioneers and government officials [2]. SME's record for about $90 \%$ of its modern offices. The Indian government "Make in India "battle will advance the dispatch of GST. Utilization duty or current pre-bundled retail items are not charged at the factory's exchange cost, however at level of the bundles most extreme selling value (MRP). This builds MRP and expands customer costs. Under GST, the producer makes good on charges while buying crude materials for the item. This sum can be credited to the following affiliate until the item arrives at the end purchaser [3]. This will incredibly help the taxation rate. This sets the energy at which two records pass. Throughout the winter semester, present the focal GST (CGST) and incorporated GST (IGST) bills alongside the primary GST bill through different significant gatherings. As per industry and government specialists, the GST termination date of April 1, 2017 is probably going to have lapsed. Organizations, particularly SME's are gathered in an assortment of enterprises. Broadened circuitous expenses GST replaces assortment of assessments, for example, extract, VAT and administration accuses of a solitary duty structure. With visit doubt, some new companies and small businesses ought to know about the negative effect they can see in photographs with the dispatch of GST. As indicated by different government offices, the GST framework will help most SME's [4].

With just a couple of months left before the usage of GST, small business owners are immersed in understanding the potential impacts of GST on their business. It's verifiable truth that SME's (small and medium enterprises) are the essential development drivers of the economy and significant supporters of the GDP. While some business owners have commended the government of India for actualizing GST, others are not extremely persuaded. To understand the general impact of GST on your business. How about we investigate the advantages and disadvantages of the new system from a small business point of view. In spite of the fact that there are a ton of points of interest to GST, SME's May have second thoughts about changing to GST is becoming acclimated to the new duty system inside a brief timeframe. Their interests may incorporate expanded consistence costs and various returns are a couple of negative impacts of GST that are probably going to influence SME. Small and medium enterprises have been considered as the essential development driver of the Indian economy for quite a long time. It further obvious from the way that today we have around 3million SME's in India contributing practically half of the modern yield and $42 \%$ of India's absolute fare [5]. For a creating nation like India and its segment decent variety, SME's have risen as the main business producing part and has given adjusted advancement across divisions. How about we look at what might be the effect of GST on small and medium enterprises.

However, before we break down the effect of GST on small and medium enterprises, we ought to understand 
how GST will extend the citizen base. Prior, any producer with a turnover of Rs.1.5 crore or less was not required to conform to the guidelines of extract obligation. In any case, with the converging of all state and local level assessments into the ambit of GST, any maker with a turnover of RS. 20lakh (others) or 10 lakh (unique classification states) or more should follow GST and its methods.

\section{A. Objective of the Study}

The objective of the paper is to study the awareness and the perception of GST among uneducated small factory owner.

\section{SALIENT FEATURES OF GST}

GST is a destination-based extract charge forced at different stages in the creation and appropriation of products and ventures. State and neighbourhood charges, amusement charges, utilization charges, additional charges, licenses and numerous different duties are joined. Duty applies to exchange costs, including bundling, charges and different expenses acquired during the bundling. You can pay full expense findings from info and capital merchandise at time of procurement, which can be thusly amortized for GST yield obligation [6].

A significant element of GST is that items and administrations are balanced and are burdened at a fixed rate until clients get to it inside the production network. Hence, charge changes give equivalent rights to huge and small businesses and citizens.

Another significant component of India's GST rollout is that it is double based. As such, both focal and different government offices will discharge GST independently. The focal government will charge CGST and the state will charge SGST individually. Be that as it may, the expense, assessment and tax collection gauges are the equivalent. This is fundamental taking into account the bureaucratic structure of the government if governments are allowed to deal with their own charges at two levels. In India, GST is forced on merchandise and ventures salary.

Another significant component of GST that should be referenced is the disposal of the falling impacts of different state and focal duties. Government charges remembered for GST incorporate VAT, amusement charge, annual duty and progressed expenses, VAT and betting assessments.

\section{Various central taxes that will be subsumed are:}

Central Excise Duty,

Additional Excise Duty,

Service tax,

Additional Custom Duty,

Special Additional Duty and

Central Sales tax

\section{POSITIVE IMPACT OF GST}

\section{- Ease of starting business}

Today, organizations in different nations require VAT enrolment. Diverse assessment governs in various states will cause entanglements and organizations will get higher procedural prizes. GST gives unified enlistments that make it simpler to begin a business and give the advantages of adding the subsequent development to a small business [7].

\section{- Market expansion}

SMEs limit their clients inside states as they will bear a definitive weight of duty on interstate deals, which decreases their client base. With execution of GST, this will be invalidated as expense credit will be moved, independent of the area of the purchaser and merchant. This will permit new businesses, SMEs and MSMEs to extend their compass across fringes.

\section{- Reduction of tax burden on new businesses}

According to the present duty structure, businesses with a yearly turnover of over Rs 5 lakh need to pay a VAT enlistment charge. The fundamental exclusion limit under GST is Rs 20 lakh and Rs 10 lakh for uncommon states, which will carry help to an enormous number of small vendors and dealers.

\section{- Elimination of distinction between goods and} services

GST guarantees that there is no uncertainty about what comprises merchandise and enterprises. This will streamline different legitimate procedures identified with bundled items. Therefore, there will never again be a differentiation between the material and the administration part, which will enormously decrease tax avoidance.

- Improved logistics and faster delivery of services

Under the GST bill, no section expense will be charged for merchandise made or sold in any piece of India. Thus, conveyance of products at interstate focuses and cost check posts will be assisted. As indicated by a CRISIL gauge, the coordinations cost for makers of mass merchandise will get decreased altogether by around 20 percent. This is relied upon to help web based business the country over.

\section{- Removal of multiple taxation}

GST will ease move of products across states and diminish the expense of working together, as the change will chop down various charges forced by state and local government.

\section{NEGATIVE IMPACT OF GST}

\section{- Registration woes}

Under the GST law, each provider of merchandise or administrations is required to be enrolled under the GST 
Act in the state or association domain from where they work, if their turnover in a budgetary year is Rs. 20 lakh or more (for exceptional class states, for example, those from the upper east, this limit is Rs 10 lakh). Along these lines, one would feel that there is no requirement for smaller players to enlist under GST [8].

$\mathrm{Be}$ that as it may, if small providers (of merchandise or benefits, or both) cause a to bury state supply, they should enlist (their turnover is unimportant). What's more, a between state supply may even signify a stockpile from Gurgaon to Delhi, the drive between which is just a couple of hours.

\section{- Concept of 'Casual Taxable Person'}

This implies somebody who at times embraces exchanges including supply of products or administrations or both, in the course or facilitation of business, regardless of whether as a head, specialist, or in some other limit, in a state or association domain where he has no fixed spot of business, additionally needs to enlist. Other than enrolling under the GST Act, the easy-going assessable individual additionally needs to pay charge at the hour of applying for registration on an expected premise.

Since the person doesn't have a position of business in that state, there would be no yield charge in that state, in this manner the state GST can't be balanced as an info charge credit. To that degree, the GST is a sunken expense for such people [9].

\section{- Composition levy mechanism is very restrictive}

It is an elective strategy for duty of assessment intended for small citizens whose turnover is up to Rs 50 lakh. The individuals who pick this mechanism are not permitted to assume input charge praise, or gather any expense from the beneficiary. To such a degree, it appears to be reasonable.

All things considered, the pace of GST under the piece demand is low. It is 2.5 percent of the turnover in the event of a producer or 1 percent for sellers. In any case, there are limitations appended. For example, indeed no between state supplies is passable. Or on the other hand so far as that is concerned, an individual deciding on a structure conspire, can't sell by means of an e-commercial center (GST requires e-commercial centers to gather charge at source).

\section{- The draconian reverse charge mechanism}

On the off chance that a small businessman (who according to as far as possible isn't required to get GST registration) supplies products or administrations to a client who is enlisted under the GST Act, the client (purchaser) is obligated to pay the GST on such a buy. This, however the purchaser likewise should self-receipt. At the end of the day, the purchaser must issue a receipt for the buy made by him from the unregistered vender
[10]. This receipt is to be transferred onto the GST framework.

\section{- Technological challenge}

Not all SMEs have the specialized aptitude to manage online frameworks. Hence, a large portion of them will require go-betweens to take them through the registration procedure. This will add to their registration cost.

\section{- Working capital blockage}

Since GST expects businesses to keep up assets as electronic credit record with the expense division, it might bring about liquidity crunch. Additionally, the brutal 'input charge credit' mechanism will likewise prompt working capital blockage.

\section{- Harsh mechanism of 'Input Tax Credit'}

Information Tax Credit is accessible to a purchaser just if the provider has paid duty inside a given window. This is one issue which a sensible level of small businesses will look in their life-cycle. Most (if not all), will have no awful 'aim' of avoidance or not paying. Now and then, the decision of 'paying compensation to the labourers on schedule' and 'taking care of a punishment to the government for deferred installment' is a cognizant call which small businesses constantly should take.

\section{- Compliance rating}

Another intriguing arrangement is the 'Consistence Rating', a framework which allocates evaluations to businesses dependent on their order, so you will know whether your provider has a 'decent or poor' rating before purchasing from them. In this manner, businesses will attempt to abstain from purchasing from individuals with 'poor' rating, which implies that individuals will do all that they can to AVOID a poor rating. What's more, the rating becomes 'poor' not only because of a postponement in recording information, yet additionally because of deferrals in instalments [11].

\section{- Added compliances for exports}

Many Start-ups/SMEs win income by sending out their administrations generally in the innovation area. Presently, with GST they need to obligatorily enroll and record returns. Truly, there is an alternative to guarantee discounts of info taxes [11].

\section{GST AND ITS IMPACT ON UNEDUCATED SMALL FACTORY OWNER}

Shefali (2016) in her examination paper on 'An impact of GST on Indian Economy', 2016 expressed that the proposed GST is a powerless endeavour to excuse circuitous expense structure. As indicated by Dani, the Government of India should consider the GST routine setup by different nations and their dropouts before its application. Almost certainly, GST will make tax assessment framework simple contrasted with the already existing heterogeneous expense framework, yet during that 
period, the Government must put forth an attempt to secure primarily the poor populace of the nation, which would be influenced because of the sanctioning of GST [12].

The Hindu date 24th September 2017article titled 'GST: MSMEs to pick up by means of better seriousness' referenced that the use of GST upgrades the intensity of MSMEs. Further, they expressed that the key advantages of MSMEs are lower dismay cost, lower cost of crude material, lower taxation rate and simplicity of working together by remembering the complexities in registration.

Rani Jacob in her exploration paper 'The Impact of GST on MSMEs' expressed the positive and negative impacts of GST on MSMEs, the positive were simpler to begin business, encourages development of business, lesser taxation rate, online consistence systems. As indicated by her, the negative impacts were particular assessment imposing, consistence cost, innovative reliance, and month to month money related readiness.

In a meeting by Adi Godrej to business line, distributed on 24 June2017, it favours GST and considers GST as an aid for Indian Economy in different perspectives. It is additionally referenced that once GST is executed there won't be chances to dodge taxes and that the rates have been examined in a way that will increase the value of the economy. This would mean considerably less desk work and in this manner, computerized disentangled methods.

The Hindu business line16May, 2017in article titled 'In what manner will GST impact MSMEs' by R. Vasudevan referenced about the sloppy MSMEs (turnover under $1.5 \mathrm{cr}$ ), which were progressing quicker than the sorted out friends on account of the underlying assessment evasion. After the authorization of GST, even these sloppy MSMEs are at risk for charge installment, as the Government has diminished the limit from $1.5 \mathrm{cr}$. to 20 lakhs.

In SME Times-Mr. Rajeev Dimri expressed that GST gives exhibit of chances and difficulties for SMEs to investigate. The government's rationale behind GST is to expand the quantity of citizens' base and not to blow up taxation rate on business/singular citizens. He further said that the GST system propelled by service of money tries to carry every resident with a total turnover of above Rs 10lakhs inside the inclusion of GST. Shakdwipee (2017) in the examination paper titled 'Estimating Awareness about Implementation of GST: A review of small business owners in Rajasthan' investigated the impression of small business owner in Rajasthan about GST, and discovered that their primary zone of center was PC programming accessibility and treatment of the equivalent [13].

As indicated by Verma, Khandelwal and Raj (2018) Goods and Services Tax (GST) was the greatest expense system implemented by Government of India on 1stJuly 2017 midnights. The general thought behind the GST usage was to streamline the current complex tax assessment framework. This exploration attempts to understand the impacts of GST on miniaturized scale, small and medium enterprises (MSME). Both positive and negative impacts have been found and noted. The paper has attempted to make an endeavour to examine the issue looked in those days and still how the businesses are overseeing after the impact of the GST [14].

According to Uppal et al (2019), as of late India saw an adjustment in its roundabout expense system. There was a lot of turmoil in the nation as individuals didn't have a lot of information and understanding for this new framework, for example Products ANDSERVICE TAX (GST). The Small business people (SBP) were the most affected portion as far as the progressions to be done in view of GST. Right now endeavour has been made to watch the mindfulness and observations about GST among SBPs. Additionally how far government is fruitful to acclimate SBPs about GST. Especially we are focussing on SBPs recognition about the new the assessment framework (for example straightforwardness, trouble on SBP's), and its organization. The outcomes shows that at first there was low level mindfulness however as the time advanced the degree of mindfulness additionally expanded among the SBPs about GST not all SBPs saw the GST framework as being sensibly simple or straightforward. In any case, it was seen that the vast majority of the SBPs were putting forth attempts to get to know the new duty system since beginning just, for example when GST bill was passed Many SBPs likewise indicated that they rely upon bookkeeping programming for keeping a legitimate record of their GST exchanges. In spite of the fact that the GST was considered as simple, yet there are some consistence costs which give a weight to SBPs. This investigation is subjective nature and it is perception based research [15].

Yadav and Kumar (2018) recommended that the accomplishment of any social plan or program is investigated through its capacity to change the ways of life and government assistance condition of individuals and their capacity to decrease imbalance in the general public and add to nation's development. Our strategy creators have pondered a grouping of tax assessment to check on this issue which we have been looking since independence. GST plan is one of them which have concentrated on government assistance condition of individuals. This paper is a hypothetical understanding of the impact of Goods and Services Tax over Indian Tax framework. GST is the main roundabout duty that straightforwardly influences all divisions and segments of our economy. The idea highlights and the structure of GST have been talked about right now. Several nations implemented this expense framework followed by France, being the primary nation to present GST. India is a bureaucratic just and thusly the GST was implemented equal by the Central and State governments as CGST and SGST separately. The present 
paper concentrated on clarifying the ideas of GST and its evolution in India. At that point it examines the issues looked by the nation regarding its usage and how could it impact the economy at its underlying stage [16].

\section{CONCLUSION}

Small factory is a developing division where enterprises enter and leave the market much of the time, so the execution of GST has greatly affected the endurance in the market. A few enterprises thought that it was helpful however dominant part confronted trouble in tolerating it. For existing enterprises, GST disentangled the expense structure, brought together the market henceforth improved the general operational efficiencies of MSME, so far the disorderly MSMEs were developing quick than the composed ones due to the assessment evasion, with GST essentially, it has made the tax assessment framework straightforward along these lines making the substances at risk for charge installment. For another business visionary, the utilization of GST, made the registration for tax collection simple, diminished them from past VAT registration. The Government has implemented GST with a perspective on long haul better possibility for the nation by different viewpoints. The merchandise and enterprises charge (GST) makes the assessment framework simple and along these lines contributing in the development of the nation. The Government applied GST by summarizing of different taxes under CGST and SGST, straightforward tax assessment, diminished crude material expense, to cut down the expense of products and ventures and the simplicity of working together in India. At first there was immense turmoil with respect to the establishment of GST, however numerous effective business people upheld it and considered it as an aid for the long haul advancement of the country.

\section{REFERENCES}

[1] Bhattacharya,G. (2002). A review to understand the challenges a prospective entrepreneur, May face in the Indian emerging economy. 22.

[2] Robert, K. (2004). Impact of GST bill on the Indian economyee, Indian journal of finance. 22 (4), 65-78.

[3] Richard, A. R. (2009). An overview of small and. Medium enterprises: past, present and future scenario, 2(2), 23-28.

[4] Kumar, R. (2017). Problems faced by entrepreneurs: A special Reference to micro and small entrepreneurs in Mumbai and Pune. 255-256.

[5] Mathew, P. M. (2011). Management and organisation review special issue the innovation and entrepreneurship ecosystem in India, Management and organisation review. 209-12.

[6] Girish, G. (2014). Basic concepts and features of good and service tax in India. International Journal of scientific Research and Management, 2(2), 542-549
[7] Shettima, M. B. (2017). Impact of GST on the Indian economy. International Journal of Engineering Technology Science and Research, 4(10), 293-298.

[8] Datey, V.S. (2017). GST ready reckoner. (4 th ed.). India: Taxmann.

[9] Gupta, S. Munindra, S. Kumar, S. K. and Hemraj, K. (2017). Good and service tax: An international comparative analysis. International Journal of Research in Finance and Marketing, 7(5), 29- 38.

[10] Shah, S. M. and Nirav R. J. (2017). Tax reform for developing viable and sustainable tax systems in India with special reference to GST. International Journal of Management, 8(1), 119-126.

[11] Agrawal, Y. K. (2017). Goods and services tax and its impact on Indian economy. IOSR Journal of Business and Management, 19(10), 26-30

[12] Shefali, D. (2016). 'Business and Economic Journal. 7(4).

[13] Shakdwipee, P (2017) Impact of GST on the Regulation of Small Business "IOSR Journal of Business and Management (IOSR-JBM) 20.7, 81-83.

[14] Verma, P. Khandelwal, S. and Raj, A. (2018). Impact of GST on the Regulation of Small Business, Journal of Business and Management. 20(7), 81-83.

[15] Uppal et al (2019). GST: Awareness and Perception of Small Business Persons' (SBPS), International Journal of Innovative Technology and Exploring Engineering. 8.

[16] Yadav, A. and Kumar, A. (2018). Indian Goods and Services Tax: A Review of its Introductory Stage and its Possible Contribution towards Sustainable Economic Development, International Journal of Management Studies. 2231-2528. 